\title{
ChemComm
}

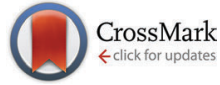

Cite this: Chem. Commun., 2017. 53, 3527

Received 30th January 2017, Accepted 7th March 2017

DOI: $10.1039 / \mathrm{c7cc00804j}$

rsc.li/chemcomm

\section{Structural insights into the EthR-DNA interaction using native mass spectrometry $\dagger$}

\author{
Daniel Shiu-Hin Chan, ${ }^{a}$ Wei-Guang Seetoh, ${ }^{a}$ Brendan N. McConnell, ${ }^{a}$ \\ Dijana Matak-Vinković, ${ }^{a}$ Sherine E. Thomas, ${ }^{\mathrm{b}}$ Vitor Mendes, ${ }^{\mathrm{b}}$ Michal Blaszczyk, ${ }^{\mathrm{b}}$ \\ Anthony G. Coyne, ${ }^{a}$ Tom L. Blundell ${ }^{b}$ and Chris Abell ${ }^{* a}$
}

EthR is a transcriptional repressor that increases Mycobacterium tuberculosis resistance to ethionamide. In this study, the EthR-DNA interaction has been investigated by native electrospray-ionization mass spectrometry for the first time. The results show that up to six subunits of EthR are able to bind to its operator.

Tuberculosis (TB) is a contagious disease caused by Mycobacterium tuberculosis (Mtb) that exerts an enormous burden on human health and wellbeing worldwide. The World Health Organization (WHO) has estimated that in 2014, TB killed 1.5 million people, while another 9.6 million people were infected. ${ }^{1}$ Progress against TB has been challenged by the rise of multidrug resistant (MDR) and extensively drug resistant (XDR) Mtb strains. 3.3\% of new cases and $20 \%$ of previously treated cases have MDR-TB, and of those, an estimated $9.7 \%$ are XDR-TB. ${ }^{1}$

Ethionamide is a second-line drug used for the treatment of MDR-TB. Mechanistically, ethionamide is a prodrug that is activated in vivo by EthA, a flavin-containing monooxygenase enzyme in Mtb, to form an ethionamide-NAD adduct. ${ }^{2}$ This adduct inhibits the 2-trans-enoyl reductase enzyme InhA, which in turn leads to the inhibition of the Mtb type II fatty acid synthase system (FAS II). ${ }^{3}$ However, the potency of ethionamide is reduced by EthR, which is a transcriptional repressor of ethA expression. ${ }^{4}$ This suggests that inhibitors of EthR activity could function as ethionamide boosters, ${ }^{5}$ allowing for lower dosages of the drug to be used.

EthR belongs to the TetR/CamR repressor protein family, whose members show high sequence homology between their $\mathrm{N}$-terminal DNA-binding domains, and is expected to bind to the DNA major groove via its helix-turn-helix (HTH) motif. ${ }^{6}$ Using DNase footprinting assays, Baulard and co-workers showed that

\footnotetext{
${ }^{a}$ Department of Chemistry, University of Cambridge, Lensfield Road, Cambridge CB21EW, UK. E-mail: ca26@cam.ac.uk

${ }^{b}$ Department of Biochemistry, University of Cambridge, 80 Tennis Court Road, CB2 1GA Cambridge, UK

$\dagger$ Electronic supplementary information (ESI) available: Methods and supplementary spectra. See DOI: 10.1039/c7cc00804j
}

EthR recognizes a $55 \mathrm{bp}$ operator sequence within the ethA- $R$ intergenic region. ${ }^{4}$ Subsequent surface plasmon resonance (SPR) analysis suggested that up to eight units of EthR could bind cooperatively to a $62 \mathrm{bp}$ sequence $\left(\mathrm{DNA}_{62}\right)$ encompassing the operator site (Fig. S1, ESI $\dagger$ ). ${ }^{4}$ There are numerous X-ray crystal structures of the EthR dimer in complex with various smallmolecule ligands, ${ }^{7,8}$ but the structure of the EthR-DNA complex has not yet been solved.

Native electrospray ionization-mass spectroscopy (ESI-MS) is an ideal technique for the study of the interactions and stoichiometries of macromolecular complexes. ${ }^{9,10}$ A large body of work has established that the native structure and composition of biomolecular complexes can be adequately maintained as solution species are transferred into the gas phase during the electrospray process. However, compared to the application of ESI-MS for multi-protein complexes, fewer studies on proteinDNA complexes have been reported. ${ }^{11-14}$ Analysis of protein-DNA complexes containing large DNA sequences using positive-ion native MS is complicated by the heterogeneity of cation adduction and as well as difficulties with achieving a stable electrospray. ${ }^{12,14}$ In this work, native MS was used to provide structural insights into the EthR-DNA interaction. Our results indicate that up to six subunits of EthR are able to bind to its operator.

Mass spectra of histidine-tagged EthR or EthR-DNA complexes were obtained by nano-electrospray ionization (nESI) from a hybrid quadrupole time-of-flight (qTOF) SYNAPT HDMS (Waters) instrument. The native MS spectrum of EthR alone confirmed the dimeric nature of EthR in solution, with the charge state distribution being centered around the 13+ state (Fig. 1a). The observed mass of dimeric EthR (50475 $\pm 97 \mathrm{Da})$ was consistent with the theoretical mass of the dimer of the construct (50 $456 \mathrm{Da}$ ). A small amount of monomeric EthR was also observed, at about $5 \%$ of the total protein content.

The native mass spectrum of $\mathrm{DNA}_{62}$ alone showed that while $\mathrm{DNA}_{62}$ existed primarily in its expected duplex state centered around the $10+$ charge state, a fraction of the DNA was singlestranded $\left(\mathrm{DNA}_{\mathrm{ss} 62}\right)$, which could be due to an excess of one of the two complementary oligonucleotides (Fig. 1b). DNA $\mathrm{m} / \mathrm{z}$ signals 


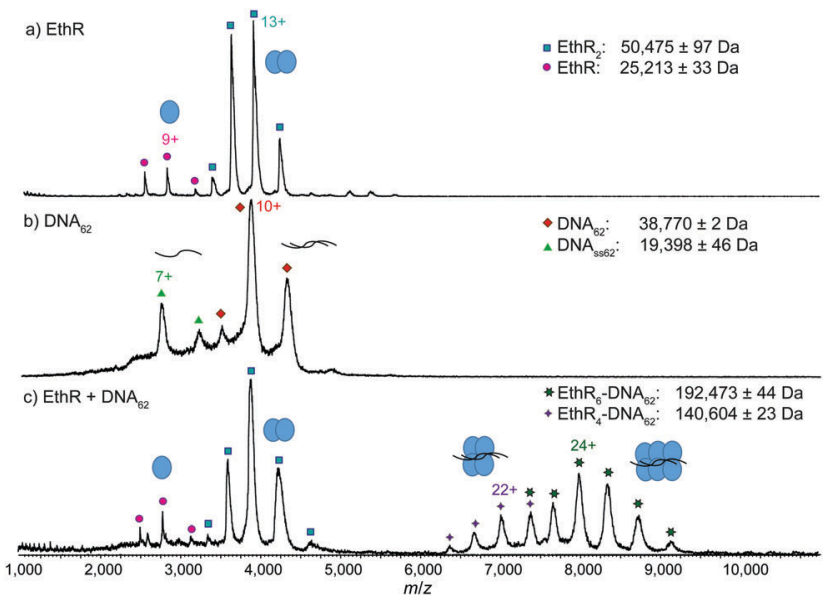

Fig. 1 Native MS reveals the formation of EthR ${ }_{4}-D N A$ and $E$ th $R_{6}-D N A$ complexes. MS spectra of (a) EthR alone showing that the protein exists predominantly as the dimer, (b) DNA $A_{62}$ alone, and (c) a mixture of EthR and $D_{N A_{62}}$ in a 8:1 ratio, showing the formation of both EthR $R_{4}-D^{2} A_{62}$ and EthR $_{6}-\mathrm{DNA}_{62}$ complexes.

were generally broad, which could be a result of the large amount of cations that must be adducted to the polyanionic DNA in order for the nucleic acids to be detected in positive-ion mode. ${ }^{15}$

Optimization experiments were carried out to investigate the effect of parameters on EthR-DNA formation, including $\mathrm{NH}_{4} \mathrm{OAc}$ concentration (Fig. S2, $\mathrm{ESI}^{\dagger}$ ), $\mathrm{Mg}^{2+}$ ion concentration (Fig. S3, $\mathrm{ESI} \dagger$ ), incubation time (Fig. S4, ESI $\dagger$ ), and buffer exchange conditions (Fig. S5 and S6, ESI $\dagger$ ). Under the optimized conditions, EthR $(20 \mu \mathrm{M})$ and $\mathrm{DNA}_{62}(2.5 \mu \mathrm{M})$ were mixed together in an $8: 1$ ratio and subjected to nESI-MS. Surprisingly, instead of the expected $\mathrm{EthR}_{8}-\mathrm{DNA}_{62}$ complex, only the $\mathrm{EthR}_{6}-\mathrm{DNA}_{62}$ complex $(192473 \pm 44 \mathrm{Da})$, centered around the $24+$ state, and the $\mathrm{EthR}_{4}-\mathrm{DNA}_{62}$ complex $(140604 \pm 23 \mathrm{Da})$, centered around the $22+$ state, were detected (Fig. 1c). The observed masses are about $1 \%$ higher than the theoretical masses of 189555 and $139099 \mathrm{Da}$ for the $\mathrm{EthR}_{6}-\mathrm{DNA}_{62}$ and $\mathrm{EthR}_{4}-\mathrm{DNA}_{62}$ species, respectively, which can be attributed to the adduction of weakly-bound molecules or ions. The EthR $\mathrm{E}_{6}-\mathrm{DNA}_{62}$ and $\mathrm{EthR}_{4}-\mathrm{DNA}_{62}$ complexes are presumably formed by the assembly of three or two EthR dimers, respectively, onto the DNA. In contrast, no protein-DNA complexes were observed by native MS when EthR was mixed with a random 55 bp sequence $\left(\mathrm{DNA}_{\mathrm{R} 55}\right)$ in a $8: 1$ or $12: 1$ ratio (Fig. S7, ESI $\dagger$ ), indicating that the complexes formed between EthR with its operator $\mathrm{DNA}_{62}$ were specific.

The proportion of EthR and $\mathrm{DNA}_{62}$ was varied in order to investigate whether alternative protein-DNA complexes could be formed at different protein to DNA ratios. At a $6: 1$ or $7: 1$ ratio of EthR to $\mathrm{DNA}_{62}$, the $\mathrm{EthR}_{4}-\mathrm{DNA}_{62}$ and $\mathrm{EthR}_{6}-\mathrm{DNA}_{62}$ complexes were detected as the major and minor species, respectively, and some free DNA could also be observed (Fig. S8a and $\mathrm{b}, \mathrm{ESI} \dagger)$. The relative intensity of free $\mathrm{DNA}_{62}$ in the native mass spectra was much higher than expected for a slight excess of DNA over protein, which could be due to the greater ionization efficiency of DNA compared to the protein-DNA complex, as has been previously reported. ${ }^{11}$ As the proportion of EthR was increased to $8: 1$, the $\mathrm{EthR}_{6}-\mathrm{DNA}_{62}$ complex became the predominant protein-DNA species, and only free protein could be detected (Fig. S8c, ESI $\dagger$ ). Even at a 12:1 ratio of EthR to $\mathrm{DNA}_{62}$, the $\mathrm{EthR}_{6}$-DNA complex was the largest species detected and no evidence of non-specific binding giving rise to higher oligomeric entities could be observed (Fig. S8d, ESI $\dagger$ ). A small amount of the $\mathrm{EthR}_{5}-\mathrm{DNA}_{62}$ complex was also sometimes observed (Fig. S9, ESI $\dagger$ ), which could presumably be formed from the association of a monomeric EthR subunit with a $\mathrm{EthR}_{4}-\mathrm{DNA}_{62}$ complex. However, the relatively low abundance of the $\mathrm{EthR}_{5}-\mathrm{DNA}_{62}$ complex and the $\mathrm{EthR}_{3}-\mathrm{DNA}_{37}$ complex (see below) compared to complexes containing an even number of EthR subunits suggests that their biological relevance may be relatively minor. An alternative interpretation is that these odd-numbered species may represent transient intermediates during protein-DNA complex formation.

The stoichiometric heterogeneity of the protein-DNA species observed by native MS could possibly account for the difficulties in obtaining an X-ray crystal structure of the EthR-DNA complex thus far. A longer $106 \mathrm{bp}$ DNA sequence $\left(\mathrm{DNA}_{106}\right)$ encompassing the entire ethA-R intergenic region also gave rise to $\mathrm{EthR}_{6}-\mathrm{DNA}_{106}$ and $\mathrm{EthR}_{4}-\mathrm{DNA}_{106}$ complexes when incubated with EthR (Fig. S10, ESI $\dagger$ ), however the quality of the native mass spectra was reduced.

Next, EthR was incubated separately with the DNA duplexes $\mathrm{DNA}_{37}$ and $\mathrm{DNA}_{36}$ (Fig. S1, ESI $\dagger$ ), and native mass spectra of the resulting complexes were recorded. In the SPR experiments reported previously, ${ }^{4}$ each $\mathrm{DNA}_{37}$ duplex bound to an average of 4.5 EthR molecules, whereas with $\mathrm{DNA}_{36}$, protein-DNA binding was greatly decreased. In native MS, a mixture of EthR $(15 \mu \mathrm{M})$ and $\mathrm{DNA}_{37}(2.5 \mu \mathrm{M})$ produced mostly the $\mathrm{EthR}_{4}-\mathrm{DNA}_{37}$ complex, centered around the 19+ charge state, along with some of the $\mathrm{EthR}_{2}-\mathrm{DNA}_{37}$ complex and a small amount of the $\mathrm{EthR}_{3}-\mathrm{DNA}_{37}$ complex (Fig. 2a). With $\mathrm{DNA}_{36}$, mainly $\mathrm{EthR}_{2}-\mathrm{DNA}_{36}$ complexes

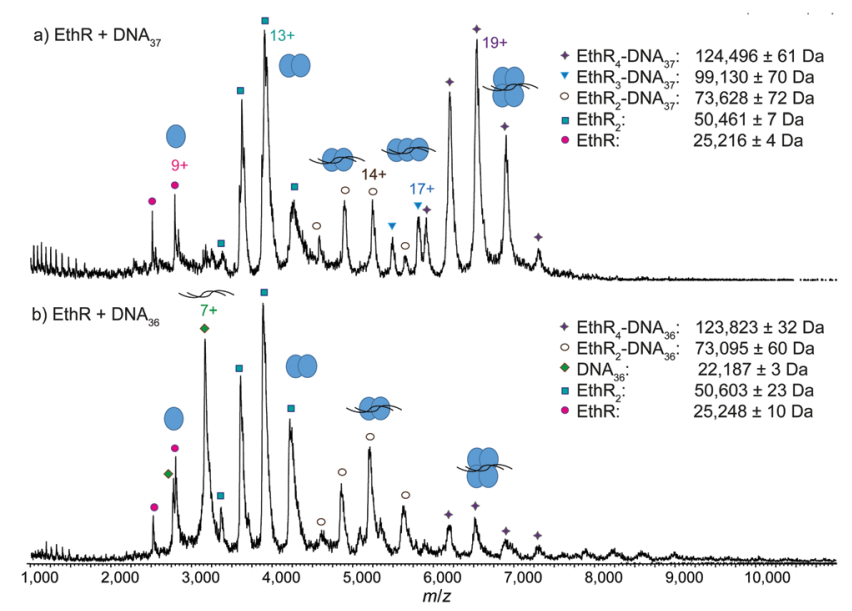

Fig. 2 Native MS showing reduced stoichiometry of EthR with the shorter $D_{N A_{37}}$ and $D A_{36}$ sequences. MS spectra of (a) EthR and $D N A_{37}$ in a $6: 1$ ratio, showing the formation of mainly $E$ th $R_{4}-D N A_{37}$ complex, some $E_{\text {thR }}-\mathrm{DNA}_{37}$ complex, and a trace of $\mathrm{EthR}_{3}-\mathrm{DNA}_{37}$ complex, and (b) EthR and $D_{N A} A_{36}$ in a $6: 1$ ratio, showing formation of mainly $E$ thR $R_{2}-D N A_{36}$ complex and some $\mathrm{EthR}_{4}-\mathrm{DNA}_{36}$ complex. 


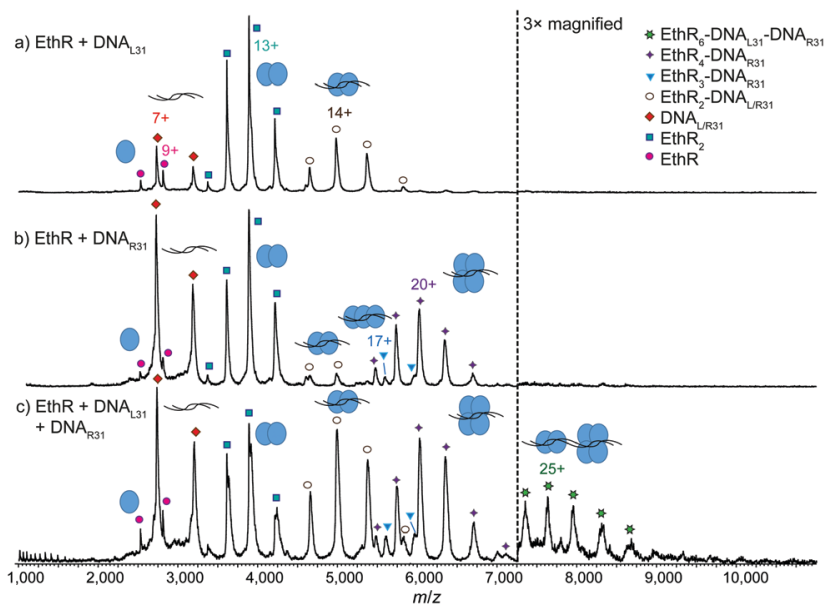

Fig. 3 Native MS showing recapitulation of the EthR $\mathrm{R}_{6}-\mathrm{DNA}$ complex from two independent half-sites. MS spectra of (a) EthR and $D N A_{L 31}$ in a $6: 1$ ratio, showing formation of mainly EthR $R_{2}$-DNA complex, and (b) EthR and $D_{N N A_{R 31}}$ in a $6: 1$ ratio, showing formation of mainly EthR $R_{4}-D N A$ complex, along with a small amount of EthR $R_{2}-D N A$ and $E$ th $R_{3}-D N A$ complexes. (c) When EthR was mixed with both $D N A_{L 31}$ and $D N A_{R 31}$, a small amount of the putative $E$ thR $R_{6}-D N A_{L 31}-D N A_{R 31}$ complex was formed.

were formed, along with a small amount of the $\mathrm{EthR}_{4}-\mathrm{DNA}_{36}$ complex (Fig. 2b). Furthermore, significant quantities of both unbound protein and DNA were observed, which is consistent with the greatly diminished binding capacity of EthR to $\mathrm{DNA}_{36}$.

To further investigate the EthR-DNA interaction, DNA $_{62}$ was split into two half-sites, the left-hand site $\left(\mathrm{DNA}_{\mathrm{L} 31}\right)$ and the right-hand site $\left(\mathrm{DNA}_{\mathrm{R} 31}\right)$ (Fig. S1, ESI $\dagger$ ). Each site contained one copy of an imperfect direct repeat that was thought to be responsible for the EthR-DNA binding interaction. ${ }^{4}$ When EthR $(15 \mu \mathrm{M})$ was incubated with $\mathrm{DNA}_{\mathrm{L} 31}(2.5 \mu \mathrm{M})$, only EthR $_{2}-\mathrm{DNA}_{\mathrm{L} 31}$ complexes were formed (Fig. 3a). On the other hand, mainly EthR $_{4}-\mathrm{DNA}_{\mathrm{R} 31}$ complexes were observed with $\mathrm{DNA}_{\mathrm{R} 31}$, along with a small amount of $\mathrm{EthR}_{2}-\mathrm{DNA}_{\mathrm{R} 31}$ and EthR $_{3}-\mathrm{DNA}_{\mathrm{R} 31}$ species (Fig. 3b). As before, the significant quantities of both unbound protein and DNA that are observed suggests that the interactions between EthR and the individual half-sites are relatively weak.

Intriguingly, when EthR was incubated with both $\mathrm{DNA}_{\mathrm{L} 31}$ and $\mathrm{DNA}_{\mathrm{R} 31}$ at the same time, a small amount of higher-order species could be detected that could be putatively assigned as the $\mathrm{EthR}_{6}-\mathrm{DNA}_{\mathrm{L} 31}-\mathrm{DNA}_{\mathrm{R} 31}$ complex (189872 $\pm 23 \mathrm{Da}$ ) (Fig. 3c). This complex could be formed from the association of the EthR $_{2}-\mathrm{DNA}_{\mathrm{L} 31}$ complex with the $\mathrm{EthR}_{4}-\mathrm{DNA}_{\mathrm{R} 31}$ complex in solution. This interaction appears to be asymmetric, as homodimeric $\left(\mathrm{EthR}_{2}-\mathrm{DNA}_{\mathrm{L} 31}\right)_{2}$ or $\left(\mathrm{EthR}_{4}-\mathrm{DNA}_{\mathrm{R} 31}\right)_{2}$ species were not detected when EthR was treated with $\mathrm{DNA}_{\mathrm{L} 31}$ or $\mathrm{DNA}_{\mathrm{R} 31}$ separately. Additionally, $\mathrm{DNA}_{\mathrm{L} 31}$ and $\mathrm{DNA}_{\mathrm{R} 31}$ do not directly associate with each other in the absence of EthR (Fig. S11, ESI $\dagger$ ), indicating that some kind of communication must exist between EthR and the DNA in order to form the putative $\mathrm{EthR}_{6}-\mathrm{DNA}_{\mathrm{L} 31}-\mathrm{DNA}_{\mathrm{R} 31}$ complex.

The EthR-DNA interaction was also investigated using isothermal titration calorimetry (ITC). EthR was titrated into DNA $_{62}$, generating a complex, non-sigmoidal binding isotherm
(Fig. S12, ESI $\dagger$ ) that was analyzed using AFFINImeter software (S4SD). A stoichiometric equilibrium binding model was designed that assumed the stepwise formation of the $\mathrm{EthR}_{6}$-DNA complex from free EthR dimers and $\mathrm{DNA}_{62}$, proceeding through $\mathrm{EthR}_{2}-\mathrm{DNA}$ and $\mathrm{EthR}_{4}$-DNA intermediates (i.e., $\mathrm{EthR}_{2}+\mathrm{DNA}_{62} \rightleftharpoons$ EthR $\left._{2}-\mathrm{DNA}_{62} \rightleftharpoons \mathrm{EthR}_{4}-\mathrm{DNA}_{62} \rightleftharpoons \mathrm{EthR}_{6}-\mathrm{DNA}_{62}\right)$. Fitting of the data to this model revealed a stoichiometry of $2.9 \pm 0.1$ EthR dimers per duplex of $\mathrm{DNA}_{62}$, which is consistent with the native MS data. The binding affinities of the first and second dimers to $\mathrm{DNA}_{62}$ were identical within experimental error $\left(K_{\mathrm{D}(1)}=\right.$ $\left.3.8 \pm 0.8 \mu \mathrm{M}, K_{\mathrm{D}(2)}=3.6 \pm 0.6 \mu \mathrm{M}\right)$. The third EthR dimer binds to $\mathrm{DNA}_{62}$ with weaker affinity $\left(K_{\mathrm{D}(3)}=10 \pm 3 \mu \mathrm{M}\right)$. The EthR-DNA 62 binding affinities derived from ITC in this work are about an order of magnitude weaker than those previously determined by SPR for the EthR-DNA 106 interaction (average $K_{\mathrm{D}}=146 \mathrm{nM}$ ). ${ }^{4}$

The calculated thermodynamic parameters indicate that the binding of the first EthR dimer to DNA is entropically favorable $\left(T \Delta S=+12.1 \pm 0.4 \mathrm{kcal} \mathrm{mol}^{-1}\right)$ but enthalpically unfavorable $\left(\Delta H=+4.7 \pm 0.4 \mathrm{kcal} \mathrm{mol}^{-1}\right)$ (Fig. 4). The favorable increase in entropy may be due to the release of countercations or solvent molecules that were associated with the DNA. ${ }^{16}$ However, the enthalpic penalty of binding stands in contrast to that observed for most major groove-binding proteins. ${ }^{17}$ This suggests that significant structural rearrangement takes place in EthR and/or the DNA to accommodate binding of the first EthR dimer. Similar to what has been observed with QacR, ${ }^{18}$ which binds to DNA as a dimer of dimers, this structural rearrangement could then present the DNA in a conformation that readily accepts the second dimer, thus accounting for the positive cooperativity of the EthR-DNA interaction. Indeed, binding of the second EthR dimer is driven almost entirely by enthalpy $(\Delta H=$ $-6.2 \pm 0.6 \mathrm{kcal} \mathrm{mol}^{-1}$ ) with only a minor entropic component $\left(T \Delta S=-1.3 \pm 0.6 \mathrm{kcal} \mathrm{mol}^{-1}\right)$. The third dimer binds via a combination of favorable enthalpic $\left(\Delta H=-2.1 \pm 0.6 \mathrm{kcal} \mathrm{mol}^{-1}\right)$ and entropic $\left(T \Delta S=-4.7 \pm 0.6 \mathrm{kcal} \mathrm{mol}^{-1}\right)$ terms.

The discrepancy in the stoichiometry of the EthR-DNA complex as determined by native MS and ITC versus the

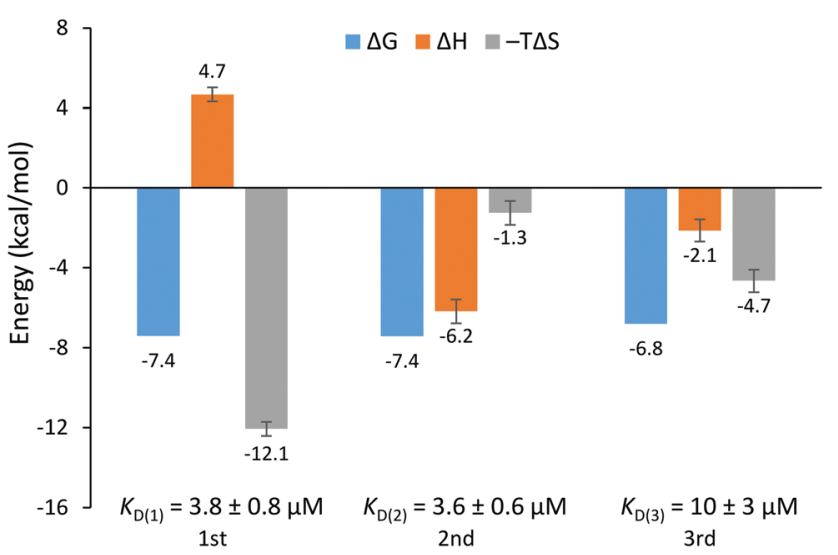

Fig. 4 Thermodynamic parameters of the EthR-DNA 62 interaction as determined by ITC. $\Delta G, \Delta H$ and $-T \Delta S$ values are shown for the binding of the first, second and third EthR dimers with DNA. Moles of EthR are given as the dimer. 
previous SPR analysis ${ }^{4}$ may be a consequence of the correction that was applied to the SPR data. In that experiment, a correction factor of 0.73 was applied to the response of DNA, reflecting the different molar refractive indices of DNA versus proteins. ${ }^{19}$ However, more recent work has shown that proteins and nucleic acids behave similarly in SPR, and so there may have been no need for this correction factor. ${ }^{20}$ When this is taken into account, the previous SPR data instead suggest that each DNA $_{62}$ duplex binds to 6.3 EthR molecules, while each $\mathrm{DNA}_{37}$ duplex binds to 3.3 EthR molecules, both numbers being consistent with the present work.

In conclusion, structural insights into the interaction between EthR and its operator have been obtained by native MS. While EthR was observed to exist as a dimer in solution as expected, the interaction of EthR with the full-length operator produced EthR ${ }_{6}-\mathrm{DNA}$ and $\mathrm{EthR}_{4}-\mathrm{DNA}$ complexes. The stoichiometry of the EthR-DNA complex was confirmed by ITC, which also revealed thermodynamic parameters that were consistent with a cooperative mode of binding. This study also highlights the capability of native MS to provide structural information on macromolecular assemblies, including where heterogeneous mixtures of complexes exist that are intractable to crystallization. Experiments are being conducted to provide structural-level detail of the EthR-DNA complex and to elucidate the precise mechanism of the EthR-DNA interaction.

The authors thank Eva Muñoz (AFFINImeter) for helpful discussion on the ITC analysis. D. S.-H. Chan acknowledges the support of the Croucher Foundation and the Cambridge Commonwealth, European and International Trust for receipt of a Croucher Cambridge International Scholarship. W.-G. Seetoh was supported by the Agency for Science, Technology and Research (A*STAR) Singapore (PhD sponsorship) and the Wellcome Trust Strategic Award (090340/Z/09/Z). B. N. McConnell acknowledges Cambridge Australia Scholarships for the award of a Poynton Scholarship, the Cambridge Philosophical Society and the Access to Learning Fund. S. E. Thomas is supported by the Cystic Fibrosis Trust. V. Mendes and M. Blaszczyk acknowledge the Bill \& Melinda Gates Foundation (subcontract by the Foundation for the National Institutes of Health - NIH) (OPP1024021).

\section{Notes and references}

1 World Health Organization, Global Tuberculosis Report, 2015.

2 T. A. Vannelli, A. Dykman and P. R. Ortiz de Montellano, J. Biol. Chem., 2002, 277, 12824.

3 X. Duan, X. Xiang and J. Xie, FEMS Microbiol. Lett., 2014, 360, 87.

4 J. Engohang-Ndong, D. Baillat, M. Aumercier, F. Bellefontaine, G. S. Besra, C. Locht and A. R. Baulard, Mol. Microbiol., 2004, 51, 175.

5 N. Willand, B. Dirie, X. Carette, P. Bifani, A. Singhal, M. Desroses, F. Leroux, E. Willery, V. Mathys, R. Deprez-Poulain, G. Delcroix, F. Frenois, M. Aumercier, C. Locht, V. Villeret, B. Deprez and A. R. Baulard, Nat. Med., 2009, 15, 537.

6 J. L. Ramos, M. Martínez-Bueno, A. J. Molina-Henares, W. Terán, K. Watanabe, X. Zhang, M. T. Gallegos, R. Brennan and R. Tobes, Microbiol. Mol. Biol. Rev., 2005, 69, 326.

7 F. Frénois, J. Engohang-Ndong, C. Locht, A. R. Baulard and V. Villeret, Mol. Cell, 2004, 16, 301.

8 L. G. Dover, P. E. Corsino, I. R. Daniels, S. L. Cocklin, V. Tatituri, G. S. Besra and K. Fütterer, J. Mol. Biol., 2004, 340, 1095.

9 H. Hernandez and C. V. Robinson, Nat. Protoc., 2007, 2, 715.

10 G. R. Hilton and J. L. P. Benesch, J. R. Soc., Interface, 2012, 9, 801.

11 A. Butterer, C. Pernstich, R. M. Smith, F. Sobott, M. D. Szczelkun and J. Tóth, Nucleic Acids Res., 2014, 42, 5139.

12 A. Politis, A. Y. Park, Z. Hall, B. T. Ruotolo and C. V. Robinson, J. Mol. Biol., 2013, 425, 4790.

13 N.-T. Nguyen-Huynh, J. Osz, C. Peluso-Iltis, N. Rochel, N. Potier and E. Leize-Wagner, Biophys. Chem., 2016, 210, 2.

14 V. Gabelica, C. Vreuls, P. Filée, V. Duval, B. Joris and E. D. Pauw, Rapid Commun. Mass Spectrom., 2002, 16, 1723.

15 F. Rosu, S. Pirotte, E. D. Pauw and V. Gabelica, Int. J. Mass Spectrom., 2006, 253, 156.

16 D. C. Mikles, V. Bhat, B. J. Schuchardt, C. B. McDonald and A. Farooq, J. Mol. Recognit., 2014, 27, 82.

17 P. L. Privalov, A. I. Dragan, C. Crane-Robinson, K. J. Breslauer, D. P. Remeta and C. A. S. A. Minetti, J. Mol. Biol., 2007, 365, 1.

18 M. A. Schumacher, M. C. Miller, S. Grkovic, M. H. Brown, R. A. Skurray and R. G. Brennan, EMBO J., 2002, 21, 1210.

19 C. Speck, C. Weigel and W. Messer, EMBO J., 1999, 18, 6169.

20 C. Di Primo and I. Lebars, Anal. Biochem., 2007, 368, 148. 